\title{
LA IMPRONTA DEL FERROCARRIL PEÑARROYA-FUENTE DEL ARCO EN EL TERRITORIO, COMO EJEMPLO DE PAISAJE MODIFICADO POR LA INGENIERÍA*
}

\author{
THE IMPRINT OF THE PEÑARROYA-FUENTE DEL ARCO RAILWAY \\ ON THE TERRITORY, AS AN EXAMPLE OF AN \\ ENGINEERING-MODIFIED LANDSCAPE
}

\author{
PedRo Plasencia Lozano \\ Universidad de Oviedo
}

\section{RESUMEN}

El texto analiza la situación actual de los restos del ferrocarril de ancho métrico Peñarroya-Fuente del Arco en el territorio. Se trata de una infraestructura puesta en servicio en 1895 y desmantelada en los años 1970 que había sido impulsada por la Sociedad Minero Metalúrgica de Peñarroya. La investigación recopila información previa ya publicada, aporta nuevos datos históricos a partir de proyectos consultados en archivos y analiza el estado actual de edificios y trazado en su contexto geográfico. Las conclusiones permiten determinar la impronta del ferrocarril estudiado en el territorio, y lo reivindican como ejemplo de paisaje modificado por la ingeniería.

Palabras clave: SMMP; ferrocarril métrico; patrimonio de la ingeniería civil, paisaje de la ingeniería civil; ingeniería del transporte.

\footnotetext{
* El texto ha sido realizado dentro del proyecto Paisajes culturales en la Extremadura meridional: una visión desde el patrimonio (HAR2017-87225-P) del Programa Estatal de Fomento de la Investigación Científica y Técnica de Excelencia, Ministerio de Economía, Industria y Competitividad, España, cuyos Investigadores Principales son los doctores Vicente Méndez Hernán y Moisés Bazán de Huerta.
} 


\section{ABSTRACT}

The paper explores the current condition of the vestiges of the railroad PeñarroyaFuente del Arco, an historical metric gauge line. The infrastructure, in service between 1895 and the 1970s, was constructed by the Sociedad Minero Metalúrgica de Peñarroya. The research combines the compilation of previous information with some other new historical data, based on fieldwork and archival research, and an analysis of the current status of the buildings and the layout in the geographical context is done. The main conclusion is the characterization of the footprints of the rail line in the territory, which can be defined as an example of an historical landscape modified by the civil engineering.

Keywords: SMMP; metric gauge line; civil engineering heritage; civil engineering landscape; transport engineering 


\section{EL FERROCARRIL MINERO DE FUENTE DEL ARCO A PEÑARROYA. INTRODUCCIÓN}

El histórico ferrocarril Fuente del Arco-Peñarroya fue una de las infraestructuras más interesantes del interior de España. Fue concluido hacia 1895, y su recorrido enlazaba un total de ocho poblaciones repartidas en dos provincias, Badajoz y Córdoba, en una extensión de $68 \mathrm{~km}$.

A lo largo de los años fue sucesivamente ampliado hacia el centro-este peninsular, y en 1927 alcanzó una extensión de 244 km, incluyendo ya entonces varias poblaciones de Ciudad Real, como Puertollano. En 1970, tras un primer periodo de esplendor y otro de decadencia, fue clausurado y desmantelado en gran parte. Hoy día son visibles aún algunas estaciones y edificios en diferente estado de conservación, junto con algunas estructuras. Además, aún permanece la mayor parte de la traza.

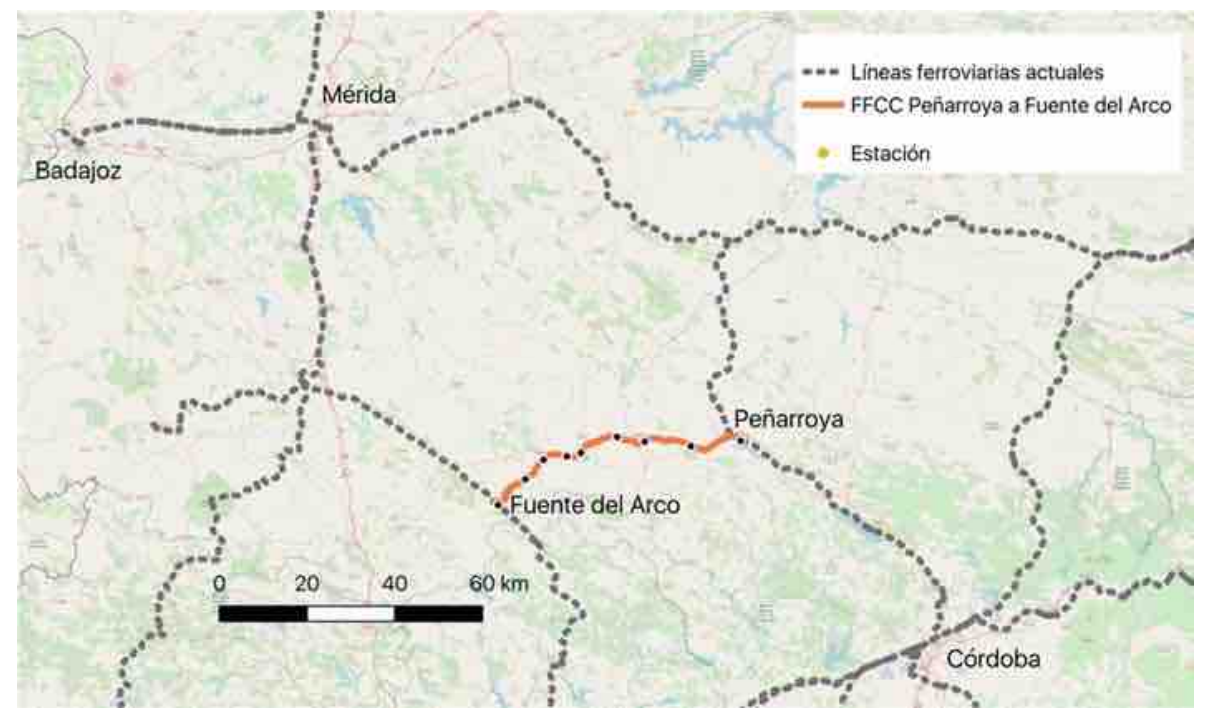

Fig. 1. Situación de la línea, encajada entre dos itinerarios sensiblemente paralelos, que existían ya y siguen aún en servicio: Zafra-Los Rosales al sur, y AlmorchónCórdoba al norte (elaboración propia)

La historia de esta línea es interesante desde múltiples puntos de vista, y existen ya diversas publicaciones que recogen datos sobre la misma. Así, se han 
estudiado algunas singularidades arquitectónicas de las estaciones ${ }^{1}$, el impacto social de su construcción ${ }^{2}$ o algunas cuestiones sobre su origen y explotación ${ }^{3}$; también es relevante el libro escrito por Molero Caballero y García-Cano Sánchez ${ }^{4}$ que recopila datos, testimonios e imágenes históricas de gran interés.

En fechas recientes, hemos escrito sobre el tramo de Fuente del Arco a Peñarroya, apuntando aspectos relativos a la situación urbanística de las estaciones con respecto a las poblaciones, las playas de vías o las peculiaridades de las estaciones extremas de la línea, que compartían espacio físico con estaciones de otras compañías ${ }^{5}$. El presente texto complementa las aportaciones anteriores a partir de dos cuestiones: en primer lugar, añade algunos datos y planos históricos recabados en el Archivo General de la Administración relacionados con la traza de la vía, las estaciones y las estructuras principales; además, repasa la permanencia de los elementos visibles aún en la actualidad y realiza un estudio de los principales elementos que son aún visibles en el paisaje.

1 Prado Rosales, L.M. 2013. "Estaciones de ferrocarril en el valle del Alto Guadiato (Córdoba): arquitectura y tipos", TST, 25, 2013, 200-230. Sobrino Simal, J. "La arquitectura ferroviaria en Andalucía. Patrimonio ferroviario y líneas de investigación", 150 Años Del Ferrocarril En Andalucía: Un Balance, Sevilla, Fundación de los Ferrocarriles Españoles, 2008.

2 Torquemada Daza, J.A. "La línea Fuente del Arco - Peñarroya - Puertollano. Construcción de un ferrocarril minero desde una perspectiva social", Tercer Congreso de Historia Ferroviaria. Gijón, 1999.

3 Peris Torner, J. "Ferrocarril de Peñarroya a Puertollano y Fuente Del Arco (SMMP)", $\mathrm{Fe}$ rrocarriles de España. https://www.spanishrailway.com/2012/04/27/ferrocarril-de-penarroya-a-puertollano-y-fuente-del-arco/. Fecha de consulta: 01/08/2019.

4 Molero Caballero, G. y García-Cano Sánchez, M. El ferrocarril Fuente Del Arco - Peñarroya - Puertollano - San Quintín (1895 - 1970). Valencia, Benaguacil. 2017

5 Plasencia Lozano, P. "Las estaciones del ferrocarril Peñarroya-Fuente del Arco. Apuntes constructivos y de diseño", Actas del XI Congreso Nacional de Historia de la Construcción. Madrid, Fundación Juan de Herrera, 2019. 


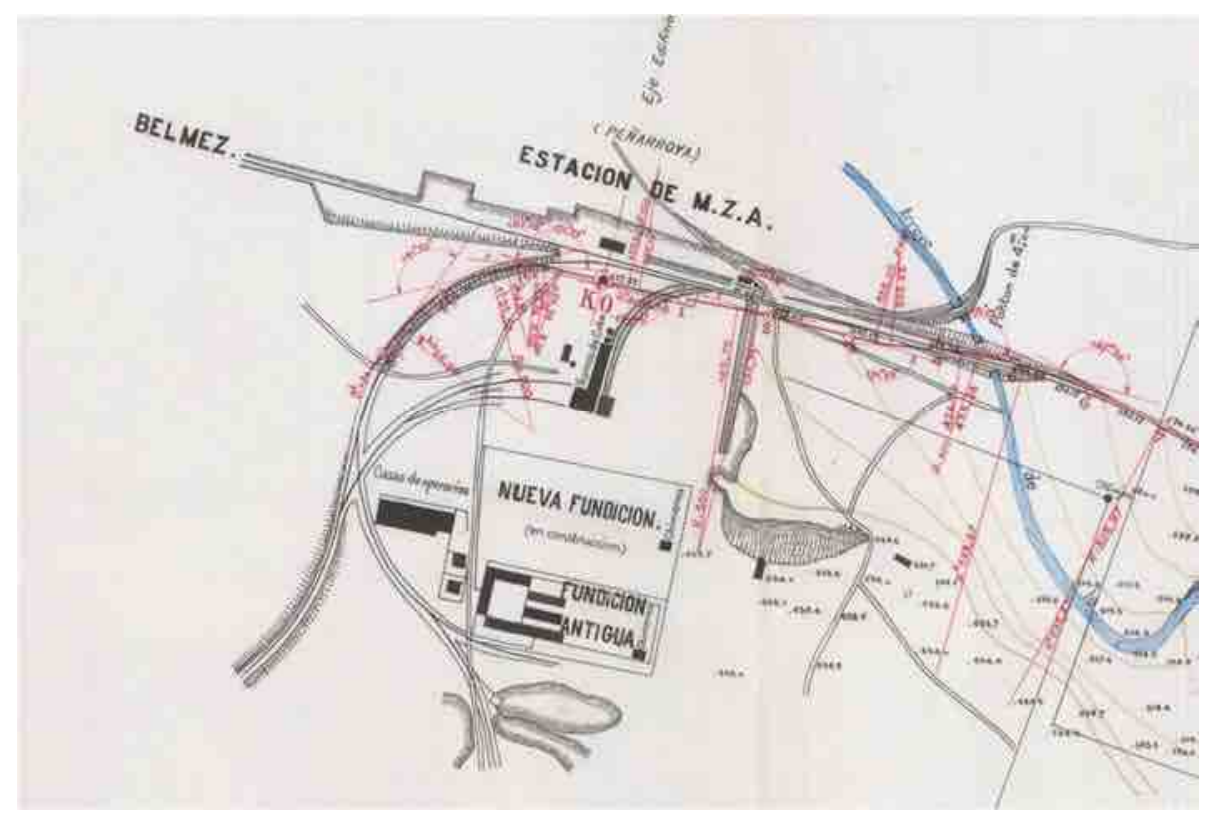

Fig. 2. Complejo de la SMMP en Peñarroya, hacia 1893 (AGA 25-07108)

\section{EL ORIGEN DE LA LÍNEA}

El origen de la línea puede buscarse en la enorme cantidad de explotaciones mineras de la zona. Una empresa había logrado adquirir un elevado número de concesiones y minas en la región a caballo entre los valles del Guadiana y del Guadalquivir, y decidió construir una línea ferroviaria para facilitar la salida de los minerales y los productos derivados de los mismos hacia la red ferroviaria ya existente. A finales del siglo XIX el ferrocarril era el modo más eficaz y versátil para distribuir mercancías, y resultaba habitual que las compañías mineras asumieran como parte de su negocio la necesidad de construir infraestructuras ferroviarias propias. 


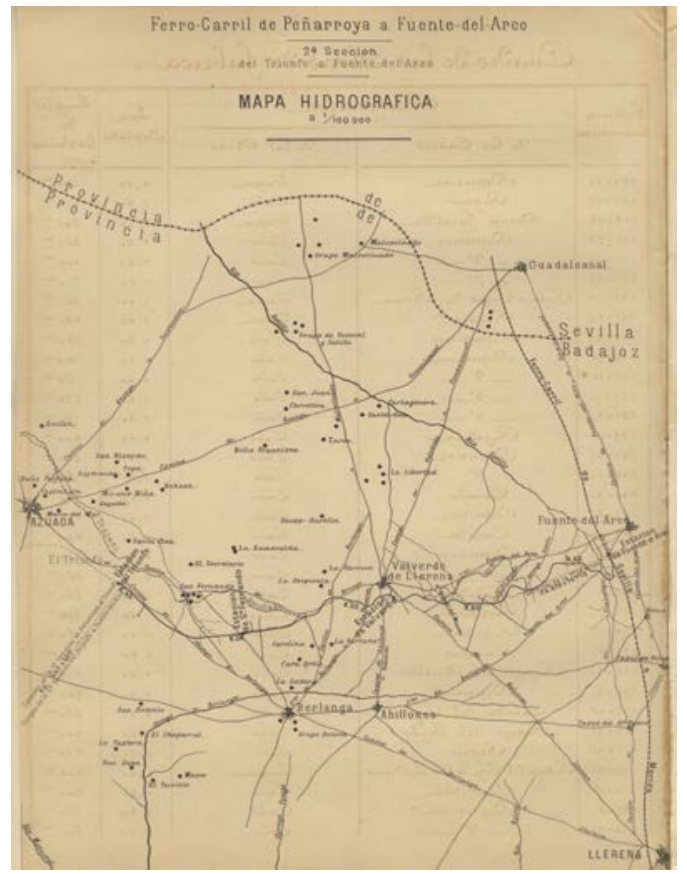

Fig. 3. Mapa de proyecto, que recoge las principales explotaciones mineras existentes entre Fuente del Arco y Azuaga (AGA 25-07112)

La empresa de la que hablamos es la Sociedad Minera y Metalúrgica de Peñarroya (SMMP), que había sido fundada en 1881 a partir de los activos de otra compañía previa, la Sociedad Hullera y Metalúrgica de Bélmez (SHMB), en cuyo capital participaban inversores extranjeros como la Casa Rothschild o Parents \& Schacken. A principios del siglo XX, la SMMP poseía la práctica totalidad de las explotaciones mineras en la región, quizá la más industrializada del interior peninsular si descontamos Madrid: contaban con más de mil concesiones entre las que destacaban 364 de carbón, 288 de cobre y 246 de plomo. Asimismo, existían explotaciones de plata en el valle de los Pedroches, de carbón en Puertollano o de hierro en la notable mina de la Jayona, junto a Fuente del Arco $^{6}$.

El plan de la SMMP era conectar con una línea la mayor parte de sus explotaciones y factorías de transformación, enlazando ésta con tres nodos ferroviarios ya existentes: Fuente del Arco, Peñarroya y Puertollano. A esta circunstancia se añadía la coyuntura alcista en la producción de plomo y carbón generada por la escasez de

6 Torquemada Daza, J.A. Op. Cit. 
estos materiales en los países intervinientes en la Primera Guerra Mundial, que favoreció sus exportaciones en la década de $1910^{7}$.

Antes del interés de la SMMP hubo otros intentos por construir un ferrocarril en la zona, donde se estaban ya construyendo o inaugurando los ferrocarriles entre Mérida y Sevilla, y entre Ciudad Real y Badajoz ${ }^{8}$. Así, el ingeniero Manuel Pastor trazó un primer esbozo en 1857 de una línea Fuente del Arco a Bélmez, impulsada por la compañía del Mérida-Sevilla; siete años después, la Compañía del Ferrocarril de Ciudad Real a Badajoz estudió la opción de una línea entre Fuente del Arco y Peñarroya. Ambas compañías fueron absorbidas por la MZA, quien nunca llegó a iniciar las obras. El tercer intento fue de la Compañía del Ferrocarril de Zafra a Huelva, que llegó a tener una concesión para realizar un ferrocarril de ancho ibérico, $1.668 \mathrm{~mm}$. Antes de que las obras se pusieran en marcha, la SMMP solicitó una concesión para un ferrocarril de ancho métrico, algo completamente legal -no lo hubiera sido si el ancho hubiera sido el mismo-, y anunció el comienzo de las obras. La Zafra-Huelva perdió entonces el interés y por ello el ferrocarril presenta un ancho distinto al usual en esa zona de la península ${ }^{9}$. Finalmente, el tramo Peñarroya a Fuente del Arco quedó inaugurado el 25 de agosto de $1895^{10}$.

\begin{tabular}{|c|c|c|c|}
\hline Tramo & Fecha concesión & $\begin{array}{c}\text { Fecha } \\
\text { inauguración }\end{array}$ & $\begin{array}{c}\text { Longitud } \\
(\mathrm{km})\end{array}$ \\
\hline Peñarroya a Fuente del Arco & $11 / 06 / 1891$ & $25 / 08 / 1895$ & 68,028 \\
\hline $\begin{array}{c}\text { Puertollano a Almodóvar del } \\
\text { Campo }\end{array}$ & $19 / 06 / 1897$ & $03 / 12 / 1899$ & 7,420 \\
\hline $\begin{array}{c}\text { Almodóvar del Campo a San } \\
\text { Quintín }\end{array}$ & $07 / 05 / 1902$ & 1903 & 17,500 \\
\hline Peñarroya a Pozoblanco & $14 / 04 / 1904$ & $05 / 08 / 1906$ & 52,914 \\
\hline Pozoblanco a Conquista & $17 / 01 / 1906$ & $03 / 07 / 1907$ & 40,075 \\
\hline Conquista a Puertollano & $08 / 07 / 1918$ & $03 / 12 / 1927$ & 56,000 \\
\hline
\end{tabular}

Tabla 1. Las líneas del ferrocarril de la SMMP ${ }^{11}$

7 Castilla Rubio, C. "Importancia e Influencia de la línea férrea Peñarroya-Puertollano en los Pedroches", Andalucia Medieval: Actas Del III Congreso de Historia de Andalucía. Córdoba, 2001, $37-48$.

8 Torquemada Daza, J.A. Op. Cit., Molero Caballero G., García-Cano Sánchez, M. Op. Cit..

9 Al renunciar la Zafra-Huelva, la SMMP podría haber construido su proyecto en ancho ibérico pero prefirió continuar adelante con el ancho métrico, que resultaba más económico

10 Las obras del primer tramo se iniciaron a finales de 1893: el ritmo de las obras fue de 3,40 meses $/ \mathrm{km}$.

11 El ferrocarril, tendría otro ramal de anchura $60 \mathrm{~cm}$ entre la mina de El Horcajo y Conquista, inaugurado en 1908, de 21,5 km. Elaboración propia, a partir de Molero Caballero G., García-Cano Sánchez, M. Op. Cit.. 


\section{EL PROYECTO DEL FERROCARRIL}

El proyecto original del ferrocarril minero data de 1892. Estaba firmado por el notable ingeniero Charles Ledoux, egresado de la École des Mines en 1861, y fundador de la SMMP; en algunos planos aparece también el nombre del ingeniero de caminos español Antonio Molina (AGA 25/07106); fue aprobado el 1 de abril de 1892 por el director general. La traza estaba dividida en dos secciones: una primera entre Peñarroya y la estación minera de Triunfo, situada en el PK 44+850, y una segunda entre Triunfo y la estación de Fuente del Arco, situada en el PK 67+974. Este proyecto sería modificado posteriormente en algunos aspectos por otro de 1894, firmado por el ingeniero de caminos Ángel Ochotorena, en cuyos planos se lee también la firma de Pablo Gal (AGA 25-07112).

El proyecto original buscaba optimizar los movimientos de tierra, e incluía un elevado número de curvas de pequeño radio: $125 \mathrm{~m}, 150 \mathrm{~m}$ o $175 \mathrm{~m}$, con desarrollos superiores a los 90 grados. Estas dimensiones resultaban estrictas incluso en ferrocarriles de vía estrecha, y con el paso del tiempo habrían limitado mucho la velocidad de las locomotoras modernas. En proyectos más antiguos, las líneas de ancho ibérico tenían unos radios mínimos considerablemente más grandes ${ }^{12}$, de al menos $400 \mathrm{~m}$, aunque debemos aclarar que una de las ventajas ofrecidas por los ferrocarriles métricos es su mayor flexibilidad en cuanto a este parámetro.

La modificación de Ochotorena y Gal optimizaba tres parámetros del proyecto de Ledux y Molina. Así, en la memoria de la modificación del segundo tramo leemos que se conseguía un acortamiento de $1.600 \mathrm{~m}$ de longitud; además, el radio mínimo de las curvas quedaba fijado en $200 \mathrm{~m}$; finalmente, las pendientes máximas se recortaban notablemente, pasando de 25 milésimas a 20 milésimas. Todo ello contribuía a mejorar las condiciones ofrecidas a los potenciales usuarios de la línea, pues son los pasajeros más que las mercancías quienes exigen una mayor velocidad comercial al transporte ferroviario. Por último, el proyecto acercaba ligeramente la estación de San Fernando a la localidad de Berlanga (no obstante, seguía estando alejada de dicha población). Apuntamos que este proyecto lleva firma de 20 mayo de 1894, y fue aprobado por César Llorens, ingeniero jefe de la división.

12 Plasencia-Lozano, P. "El proyecto no construido del ferrocarril entre Talavera de La Reina y Cáceres por Trujillo de Eusebio Page, y la modificación de Ángel Arribas", Actas del X Congreso Nacional y II Congreso Internacional Hispanoamericano de Historia de la Construcción, Madrid, Instituto Juan de Herrera, 2017, 1279-1289. 


\begin{tabular}{|c|c|c|}
\hline Parámetro & Proyecto original & Proyecto modificado \\
\hline Longitud $(\mathrm{km})$ & 23,124 & 21,524 \\
\hline $\begin{array}{l}\text { Curvas de radio } \\
\text { mínimo }\end{array}$ & $\begin{array}{l}2 \text { curvas de radio } 100 \mathrm{~m} \\
8 \text { curvas de radio } 125 \mathrm{~m} \\
26 \text { curvas de radio } 150 \mathrm{~m} \\
1 \text { curva de radio } 175 \mathrm{~m}\end{array}$ & $\begin{array}{l}\text { Radio mínimo } \\
\text { de } 200 \mathrm{~m}\end{array}$ \\
\hline Rampas & $\begin{array}{c}4 \text { rampas de } 25 \text { milésimas de } \\
1.500 \mathrm{~m} \text { de longitud } \\
1 \text { rampa de } 25 \text { milésimas de } 300 \mathrm{~m} \\
3 \text { rampas de } 20 \text { milésimas de } 1.050 \mathrm{~m} \\
2 \text { rampas de } 20 \text { milésimas, de } 550 \mathrm{~m}\end{array}$ & $\begin{array}{c}1 \text { rampa de } 20 \text { milési- } \\
\text { mas de } 950 \mathrm{~m}\end{array}$ \\
\hline
\end{tabular}

Tabla 2. Evolución del proyecto original al modificado
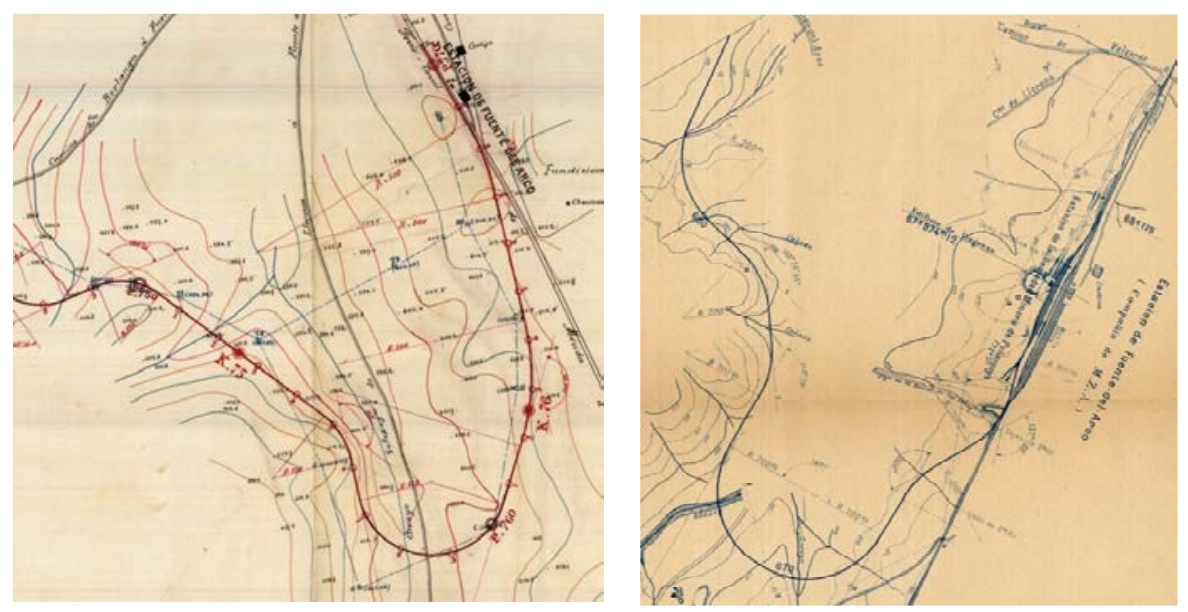

Fig. 4. Comparación entre el proyecto original (AGA 25-07106) y el modificado (AGA 25-07112) en las inmediaciones de la estación de Fuente del Arco. Puede apreciarse cómo la traza presenta variaciones notables 
4. LA IMPRONTA EN EL TERRITORIO. EL NUEVO PAISAJE GENERADO POR LA INFRAESTRUCTURA

\subsection{LA TRAZA}

El recorrido de la traza es, posiblemente, la parte de la infraestructura más relevante. En la actualidad no queda rastro de los raíles, posiblemente vendidos al peso, ni tampoco de las traviesas ni del balasto, material que puede ser reaprovechado o también vandalizado.

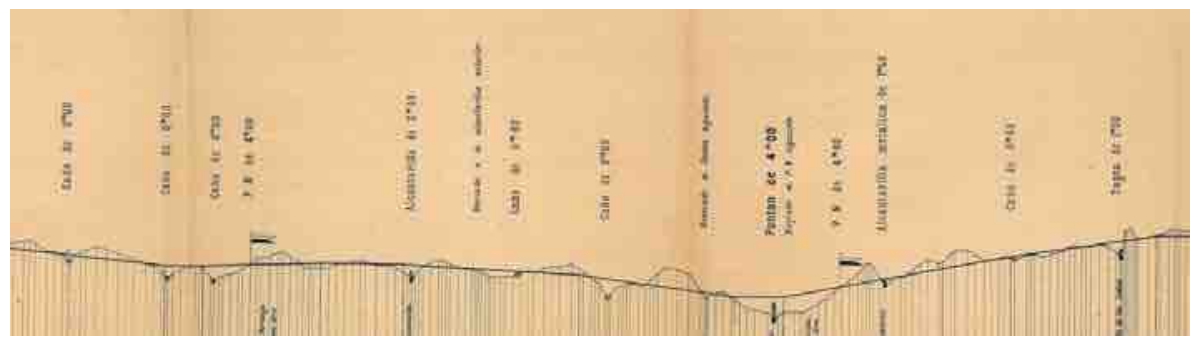

Fig. 5. Fragmento del perfil longitudinal de la línea (AGA 25-07112). Puede observarse cómo la línea férrea va adaptándose al perfil natural del terreno, más abrupto, generando una nueva realidad topográfica

Sin embargo, aún es visible el movimiento de tierras efectuado para encajar el ferrocarril en la orografía de la zona. El espacio territorial recorrido es poco accidentado, si bien incluye zonas con cerros de cierta entidad que requirieron de desmontes de varios metros de altura, encontrando varias alineaciones que se construyeron en trinchera. Asimismo, existen desniveles suaves y puntos bajos que fueron rellenados mediante terraplenes. El proyecto definía tres tipos de secciones transversales, dos en desmonte y una en terraplén:

- Una primera sección en desmonte, para el caso de terreno favorable para la excavación (tierra y esquisto descompuestos). El proyecto preveía un talud 1/1 (es decir, una pendiente del $100 \%$ ), con cunetas en U de sección hidráulica $52,5 \mathrm{~cm}^{2}$.

- Otra sección en desmonte para el caso de terreno compuesto por roca dura. En este caso el talud era considerablemente más inclinado (1/5, 
una pendiente del $500 \%$ ), con cunetas en U de sección hidráulica menor a $35 \mathrm{~cm}^{2}$.

- Una única sección en terraplén, con un talud 3/2 (una pendiente cercana al 67\%).

Estos movimientos de tierras se reproducían a lo largo de alineaciones rectas o curvas de gran amplitud y quedaban rematadas por una rasante usualmente horizontal que, en los casos más desfavorables, presentaba una pendiente del $2 \%$. El resultado es el de unas formas escasamente naturales -particularmente en el caso de las trincheras causadas por el desmonte en roca dura, por lo que pueden distinguirse visualmente con cierta facilidad. Así, la traza es aún visible a lo largo de todo el recorrido y sólo se pierde en algunas zonas muy localizadas y en las cercanías de algunas poblaciones, como Azuaga, Granja de Torrehermosa o Peñarroya donde, por mor de la propia condición periurbana del territorio, se acumulan caminos, edificaciones, nuevas infraestructuras, etc. Apuntamos también que en las zonas donde aún perviven, las laderas terraplenadas han sido colonizadas ya por las distintas especies vegetales del territorio.

En relación a la plataforma, alcanzaba una anchura de $3 \mathrm{~m}$, más las cunetas, y el balasto una anchura en coronación de $2,10 \mathrm{~m}$. Debemos pensar que el material móvil de ancho métrico no sobrepasaba los 2,50 $\mathrm{m}$ de anchura.

Podemos repasar la situación actual de la traza y su estado de conservación. Existe un tramo de vía verde, denominada Vía Verde la Jayona, que recorre 20 $\mathrm{km}$ de la antigua traza entre Fuente del Arco y Azuaga. Fue ejecutada por la Junta de Extremadura, e incorpora paneles informativos, señalización, áreas de descanso, barandillas en las zonas de desmonte, etc. Incluye además un triple tratamiento asfáltico, y permite distinguir... ${ }^{13}$. Otro tramo de vía verde se encuentra en las inmediaciones de Fuente Obejuna, ya en la provincia de Córdoba. Se trata de un itinerario de $4,5 \mathrm{~km}$, que ha sido también restaurado con cartelería, área de descanso y reposición de estructuras. El firme en este caso es tierra compactada ${ }^{14}$.

Además, partes de la traza son hoy día caminos agrícolas; algunos siguen siendo, aparentemente, públicos, mientras que otros han sido ocupados de forma ilegal por las fincas aledañas, y forman parte ya de la red de caminos de las mismas.

Posiblemente, el caso más llamativo en cuanto al devenir de la antigua traza sea un tramo recto existente en la zona de la antigua estación de Fuente

13 Más información en viasverdes.com... consultado el 8 de septiembre de 2019.

14 Más información en... consultado el 8 de septiembre de 2019. 
Obejuna. Hoy día ha sido reconvertida en una pista de aterrizaje, en el aeródromo de la localidad, y no queda rastro de ella. Creemos que esta reutilización de una antigua infraestructura ferroviaria en una infraestructura aérea debe ser un caso poco común, quizá único, que en todo caso interrumpe la continuidad de la antigua línea ferroviaria e impide, por ejemplo, la extensión de la vía verde de Fuente Obejuna en dirección a Peñarroya.

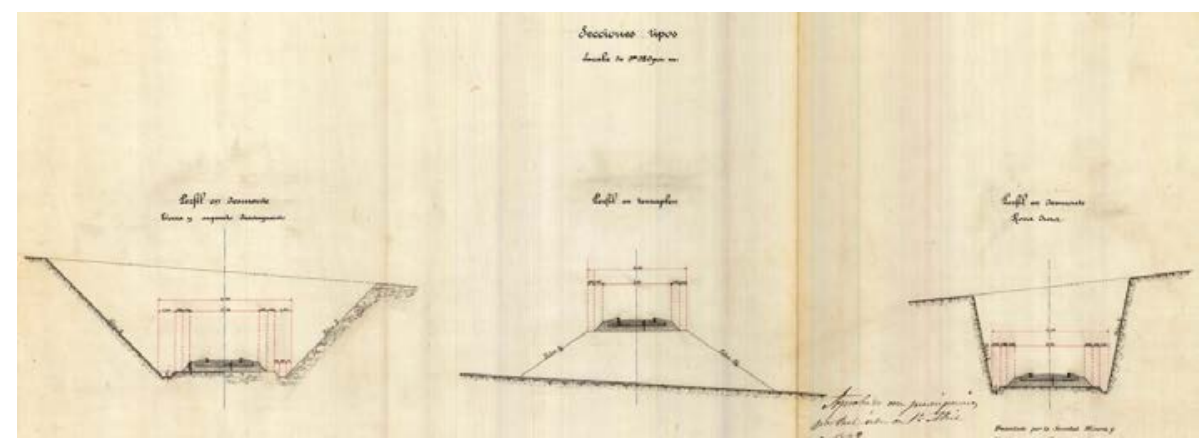

Fig. 6. Secciones tipo de la vía, en las tres posibilidades comentadas (AGA 25-07106)

\subsection{LAS EDIFICACIONES}

A lo largo de la traza fue preciso levantar una serie de edificios de distinta importancia. En las cercanías de las poblaciones se levantaron las estaciones, que aglutinaban diversas construcciones; además, en cada cruce de la vía con un camino relevante se construían casillas de guardia. Pese al reducido tamaño de los edificios construidos -no eran construcciones destinadas a prestar servicio a un gran número de usuarios-, debe destacarse la notable factura de los mismos, apreciable en la disposición de huecos, la proporcionalidad, la albañilería y la cantería ${ }^{15}$.

Los edificios principales de las estaciones del proyecto eran bastante sencillos. Consistían en una sucesión de tres zonas: un edificio de viajeros, un muelle cubierto y otro descubierto. El edificio de viajeros (de 9,00 x 7,50 m en planta, y 9,80 m de altura máxima) constaba de dos alturas: la planta baja

15 Plasencia Lozano, P. Op. Cit., 2019. Las estaciones habían sido parcialmente descritas, pero la reproducción de planos es original. 
incluía una sala de descanso con chimenea, una zona de equipajes donde se apreciaba una báscula y una mesa-mostrador, y un despacho con una mesa para el jefe de estación, un espacio para el telégrafo y una ventanilla para expedir billetes. La planta alta era la vivienda para el personal, y comprendía dos habitaciones, cocina, despensa y retrete. El almacén de mercancías, adosado al edificio, medía en planta 5,50 x 7,50 $\mathrm{m}$ y alcanzaba $10 \mathrm{~s} 6,88 \mathrm{~m}$ de altura, y estaba comunicado tanto con el despacho del edificio de viajeros como con el muelle descubierto; este último consistía en una plataforma de $8,00 \times 8,60 \mathrm{~m}$, al que podía accederse también por una rampa lateral de 5,00 $\mathrm{m}$ de anchura. La cubierta del almacén incluía una visera que volaba $4,15 \mathrm{~m}$ en horizontal, a ambos lados del edificio. Por último, había unos retretes en el exterior del edificio, algo habitual en la época.

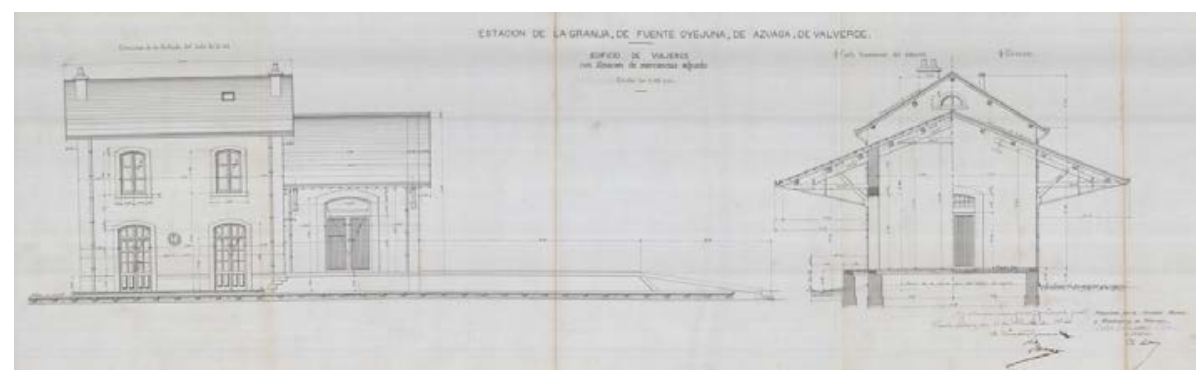

Fig. 7. Vista en alzado de los edificios de la estación (AGA 25-07106). Plano correspondiente a las estaciones de Fuente Ovejuna, Azuaga, La Granja y Valverde

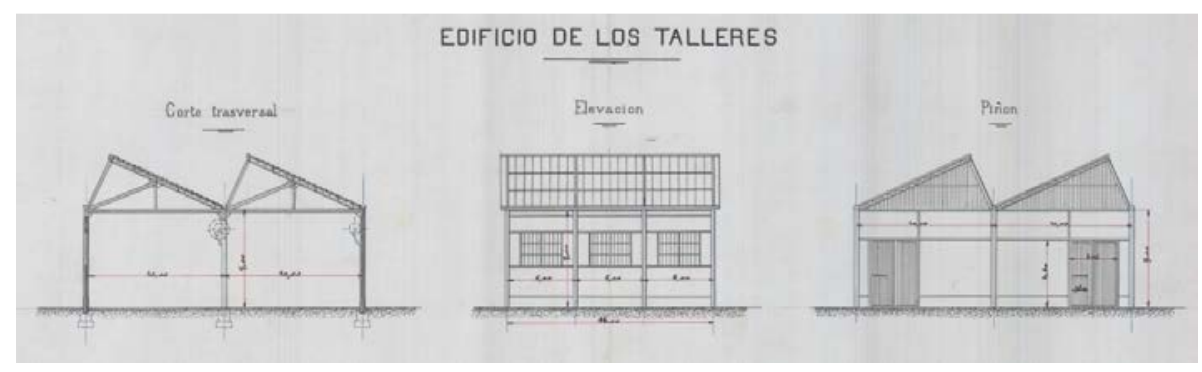

Fig. 8. Edificio de talleres, hoy día desaparecido (AGA 25-07106) 
Además, en las estaciones extremas existían otros edificios e instalaciones anexas, como talleres, depósitos para el material rodante, lampistería, depósitos para las mercancías, básculas, muelles, instalaciones para los pasajeros -cantina, aseos, incluso biblioteca-, rampas, andenes, casas para el personal de la compañía, etc. Además, en el caso que nos ocupa se da la circunstancia de que existían dos estaciones en la misma localidad - Peñarroya y Fuente del Arco-, lo que exigía una serie de instalaciones añadidas a las propias de unas estaciones de su tamaño en condiciones normales, ligadas a las labores de transbordo de mercancías: muelles, viviendas para los mozos de carga y otras edificaciones para estos operarios, etc. También existía una capilla y una escuela. Pero quizá el edificio más singular, por su tipología, era el del muelle cubierto de intercambio, un largo edificio de 22,50 m que se situaba con una vía de cada ancho a cada lado, con una serie de puertas correderas que permitía el paso directo y simultáneo de mercancías de un tren a otro. Había también un muelle descubierto de $12 \mathrm{~m}$ de longitud, con la misma finalidad (AHF B-0005-009; AHF C913-1). Este tipo de edificios sólo tenía sentido en estaciones con dos anchos diferentes, operando en el mismo espacio.

Una singularidad de las estaciones de la línea (AGA 25-07106) es que el diseño quedaba condicionado al tráfico de mercancías. La carga se realizaba desde el almacén cubierto anexado al propio edificio de la estación, y por ello el tren parado debía quedar a pocos centímetros del mismo. Esto provocó que el andén fuera proyectado entre dos vías y no junto al edificio de viajeros; como consecuencia, los pasajeros debían cruzar necesariamente una vía para poder acceder a dicho andén, y por tanto al tren.

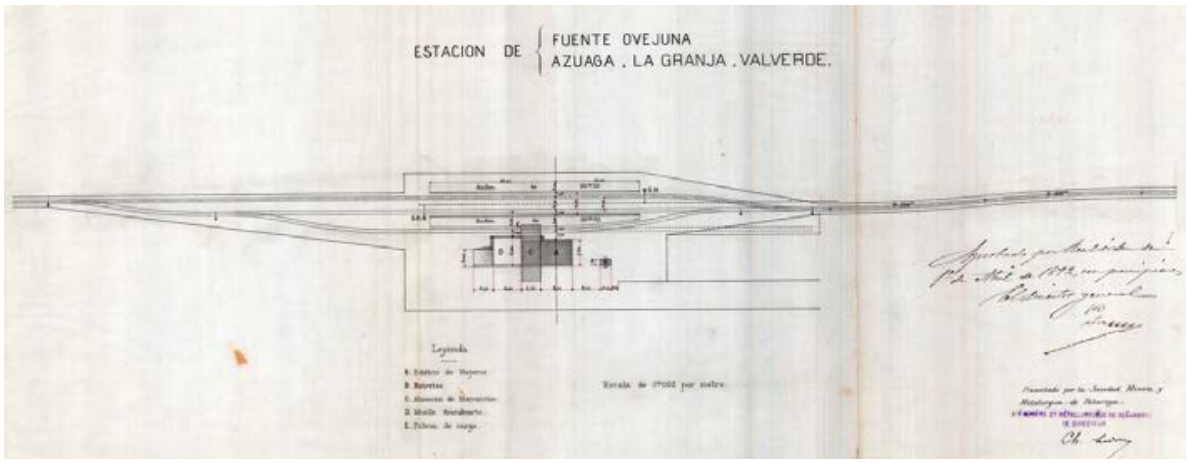

Fig. 9. Planta general de la estación (AGA 25-07106) 
Además, durante las décadas siguientes a la construcción original se realizaron distintas ampliaciones de instalaciones y edificios (AHF B-0010-001, AHF C-173-1), y del mismo modo hubo empresas ajenas a la SMMP que quisieron hacer sus propias instalaciones de carga y descarga, como el caso de la mina La Jayona (AHF B-0010-001). Por tanto, las estaciones conformaron enclaves particularmente dinámicos en cuanto a su fisionomía.

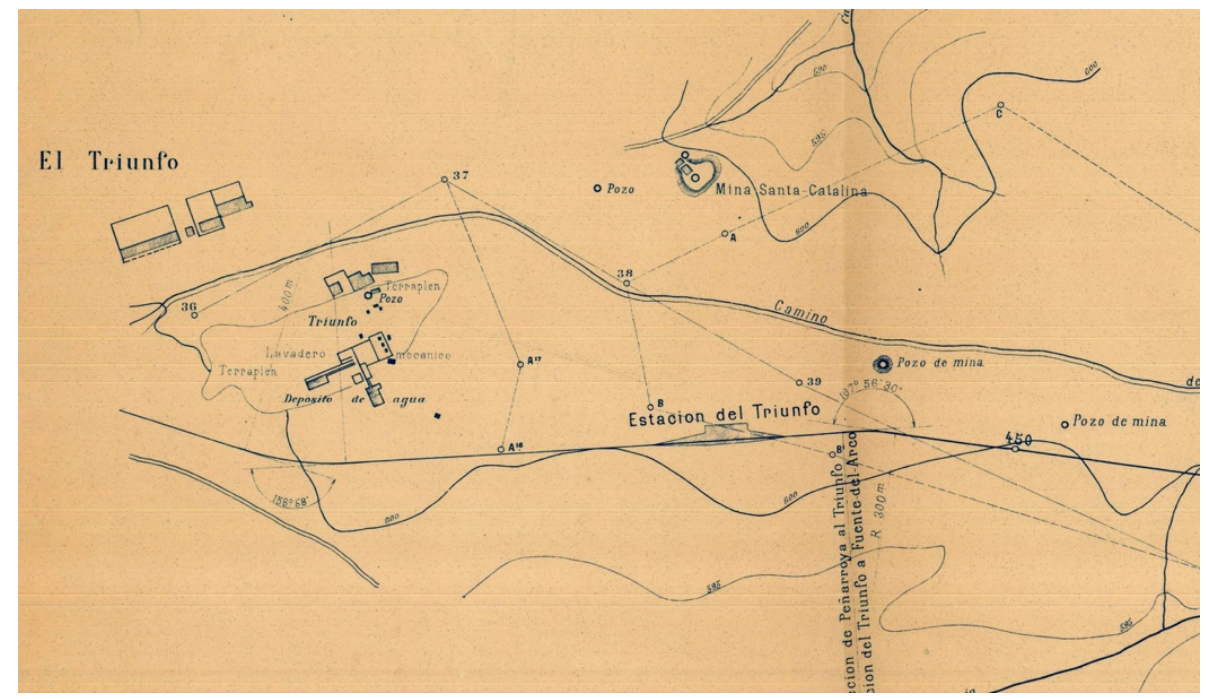

Fig. 10. Apartadero de Triunfo, con la descripción en planta de las distintas instalaciones existentes (AGA 25-07112)

En el tramo de Fuente del Arco a Peñarroya existía una estación con la consideración de apeadero. Estaba situada entre las estaciones de Azuaga y Berlanga, y daba servicio a la importante explotación minera de Triunfo (que incluía lavadero, depósitos de agua, edificios, pozos), y también a la de Santa Catalina. Hoy día la estación y las antiguas instalaciones se encuentran en ruinas, si bien son aún visibles desde la carretera EX309. La mina era de carbón, se trataba de un empalme industrial, que comprendía una vía que alcanzaba la mina, otra vía con placa giratoria que finalizaba en una cochera y un pequeño edificio, de menor entidad que los del resto de estaciones. 
Además de las estaciones, la compañía construyó un elevado número de casillas de guarda. Se trata de edificios de $5 \times 7,50 \mathrm{~m}$, con altura máxima 5,15 $\mathrm{m}$, que se situaban en los cruces entre la vía y los principales caminos para guarecer a los guardas, si bien no tenían uso de vivienda como tal. Constaban de dos estancias, una de ellas con chimenea, y servían también como almacén.

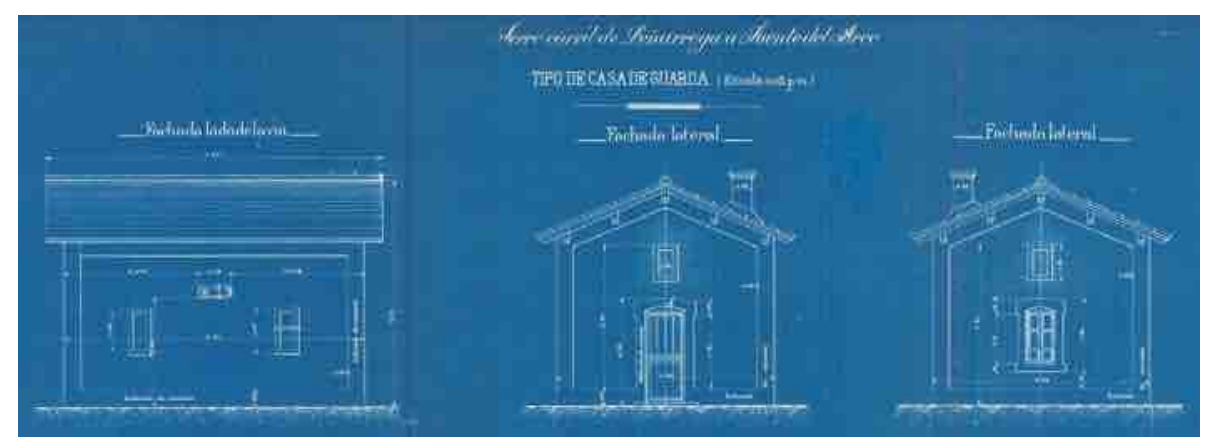

Fig. 11. Casilla de Guarda (AGA 25-07106)

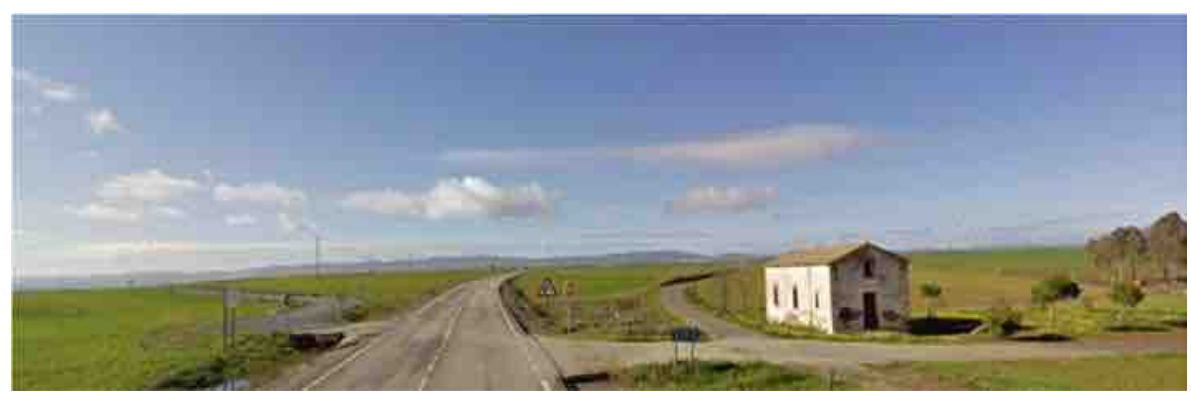




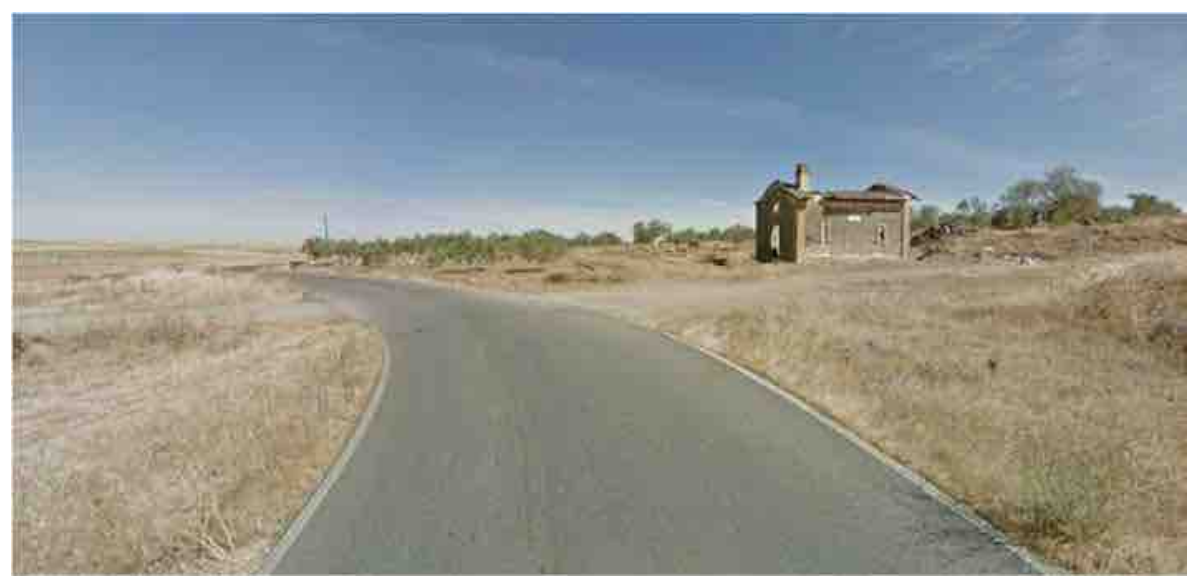

Fig. 12. Casilla de Guarda, en las cercanías de Valverde de Llerena; la actual carretera EX309 discurre paralela a la traza de la vía, visible en el territorio. En la parte inferior, otra casilla en el mismo municipio; en este caso se observa la traza que cruza, con una zona en trinchera a la derecha de la imagen (Google Street View)

Estos elementos, hoy abandonados en su mayor parte, siguen presentes en el territorio, en ocasiones como únicas edificaciones en zonas muy amplias. De algunas sólo permanecen los muros. Sin embargo, todavía marcan los puntos en los que la vía se cruzaba con caminos principales. Además, su existencia a lo largo de una traza de casi $70 \mathrm{~km}$ nos recuerda que hubo un tiempo donde todo el territorio estuvo unido bajo un mismo proyecto, una misma tipología, una misma concepción.

Otros elementos que aún pervive en algunos puntos, aun parcialmente, son los depósitos de agua, proyecto del ingeniero de caminos Antonio Molina aprobado el 21 de febrero de 1895. Estas construcciones nos relacionan de un modo directísimo con el ferrocarril, y constituían hitos del paisaje dentro de las estaciones, ya que se situaban en altura para garantizar la necesaria diferencia de cota. Pese a su simplicidad, muestra el cuidado en el detalle de la albañilería, el recercado de la puerta con el detalle del dintel o el remate de la cornisa. Las chapas se hicieron de espesor $4 \mathrm{~mm}$ y almacenaba un volumen de $28 \mathrm{~m}^{3}$. La parte de fábrica se elevaban $4 \mathrm{~m}$ sobre el terreno natural, y junto a los $2,90 \mathrm{~m}$ de la parte metálica alcanzaba a los 6,90 m. Los muros para sostenerlo medían 0,50 $\mathrm{m}$ de espesor. 

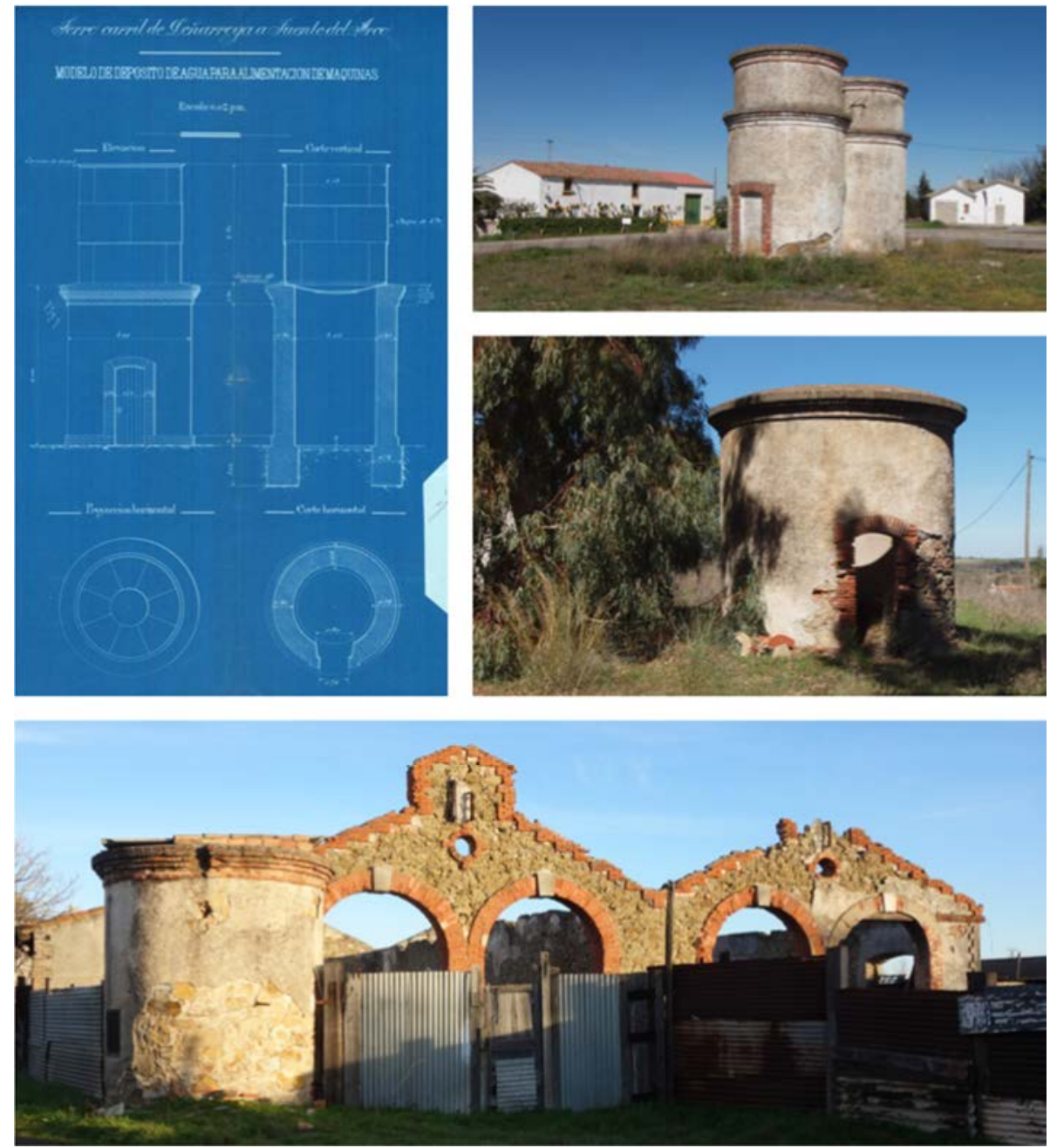

Fig. 13. Depósito de agua. Plano original (AGA 25-07106) y restos de la parte de fábrica en las estaciones de Azuaga, Fuente del Arco y Peñarroya; la última imagen incluye paramentos aún visibles de las cocheras

\subsection{LAS ESTRUCTURAS}

Como decíamos, la traza del ferrocarril recorre un espacio de orografía bastante benigna, y no fue preciso construir estructuras notables. Únicamente se proyectaron algunos puentes en cauces como los de los ríos Zújar o 
Bembézar, o sobre el arroyo San Pedro. Las estructuras consistían en vigas de acero de 6,12 y $18 \mathrm{~m}$ de luz; las más pequeñas estaban compuestas por diferentes planchas que terminaban por formar distintos perfiles en I; el canto de los puentes de $12 \mathrm{~m}$ alcanzaba los $90 \mathrm{~cm}$ de altura y su tablero sobrepasaba los 3,30 $\mathrm{m}$ de anchura. Había también, al menos, un puente de $18 \mathrm{~m}$ de luz, sobre el arroyo San Pedro (PK 5+148, en las cercanías de Peñarroya) que consistía en una celosía compuesta por dos cuchillos tipo Pratt de canto $2 \mathrm{~m}$ con montantes dispuestos cada 1,94 m, arriostrados inferiormente mediante cruces de San Andrés, y con la vía situada en el tercio inferior; fue objeto de un proyecto de refuerzo para cumplir con los nuevos requerimientos del Ministerio (AGA 2621711), que exigían soportar una locomotora de 51 toneladas (tipo 1-4-0); este proyecto fue firmado el 8 de junio de 1927 por el ingeniero C. Robledo y tenía un presupuesto total de de 26.000 pesetas.

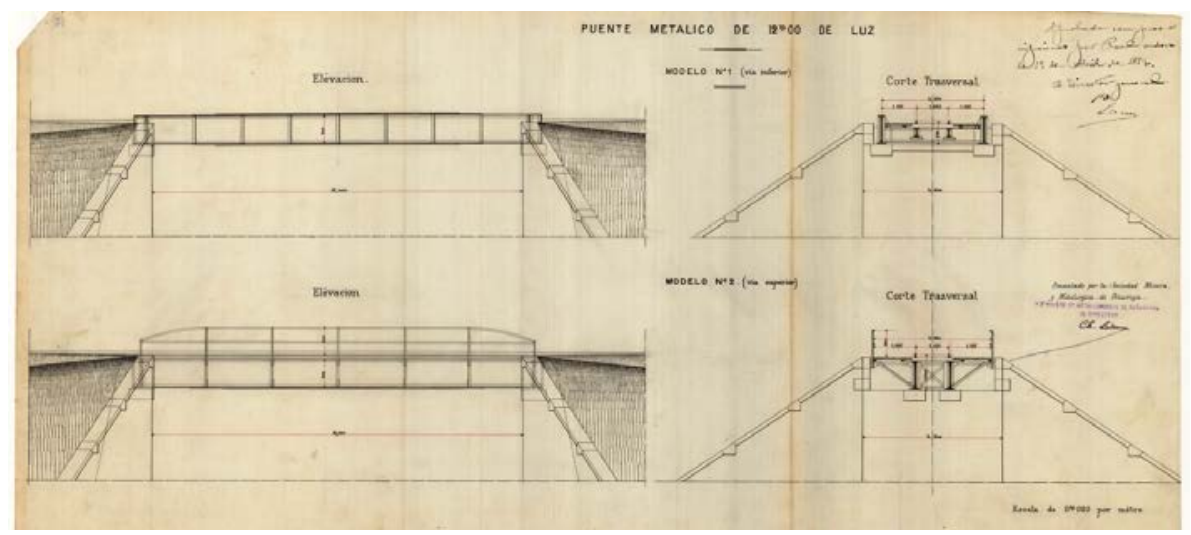

Fig. 14. Modelos de puentes para $12 \mathrm{~m}$ de luz, según proyecto (AGA 25-07106)

De todo el conjunto de puentes creemos que hoy día sólo permanecen los estribos, de ladrillo y sillería, pues las vigas posiblemente fueran vendidas al peso cuando el ferrocarril se desmanteló en los años posteriores a su cierre ${ }^{16}$. La visión de los estribos, sin vigas que permitan el paso efectivo entre ambas orillas, evoca

16 No nos resultó posible visitar algunos de estos puentes al no encontrar acceso, como el del Zújar; imaginamos que si fueron eliminadas las vigas de todos los visitados, también lo serían las del resto. 
no sólo al puente que una vez fue, sino a toda la infraestructura: el paso interrumpido se convierte en metáfora visual de la pérdida del ferrocarril en toda la comarca. Asimismo, la reposición de un puente en la citada vía verde de Fuente Obejuna funciona como símbolo de trazado recuperado para la ciudadanía.

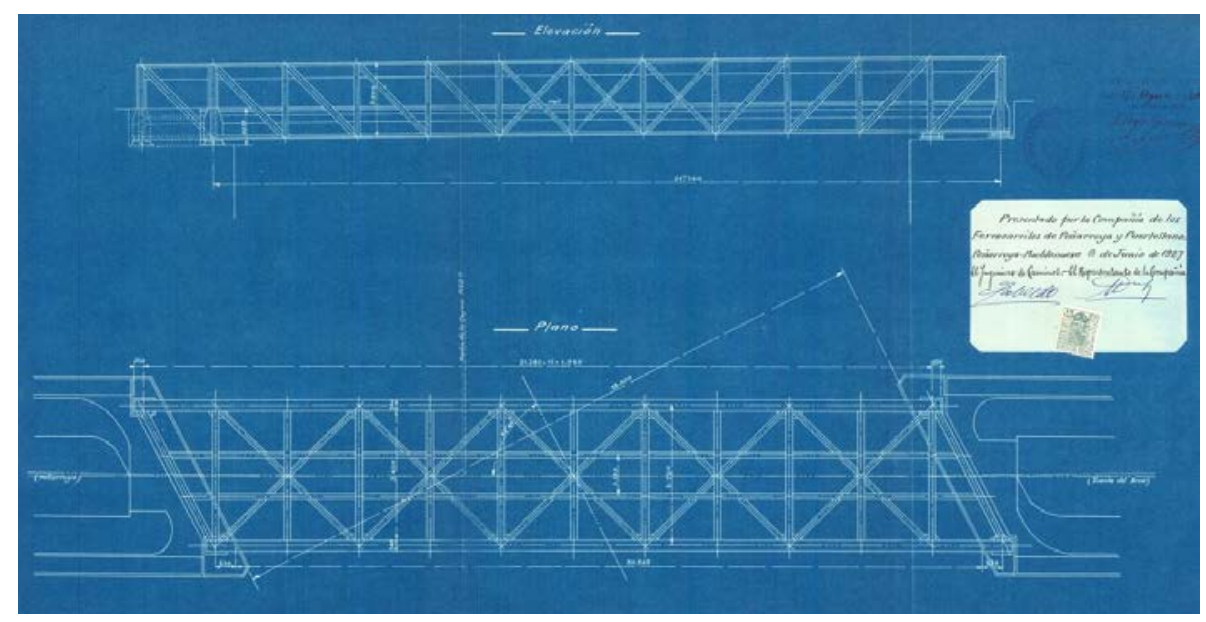

Fig. 15. Puente de $18 \mathrm{~m}$ de luz (AGA 26-2621711)

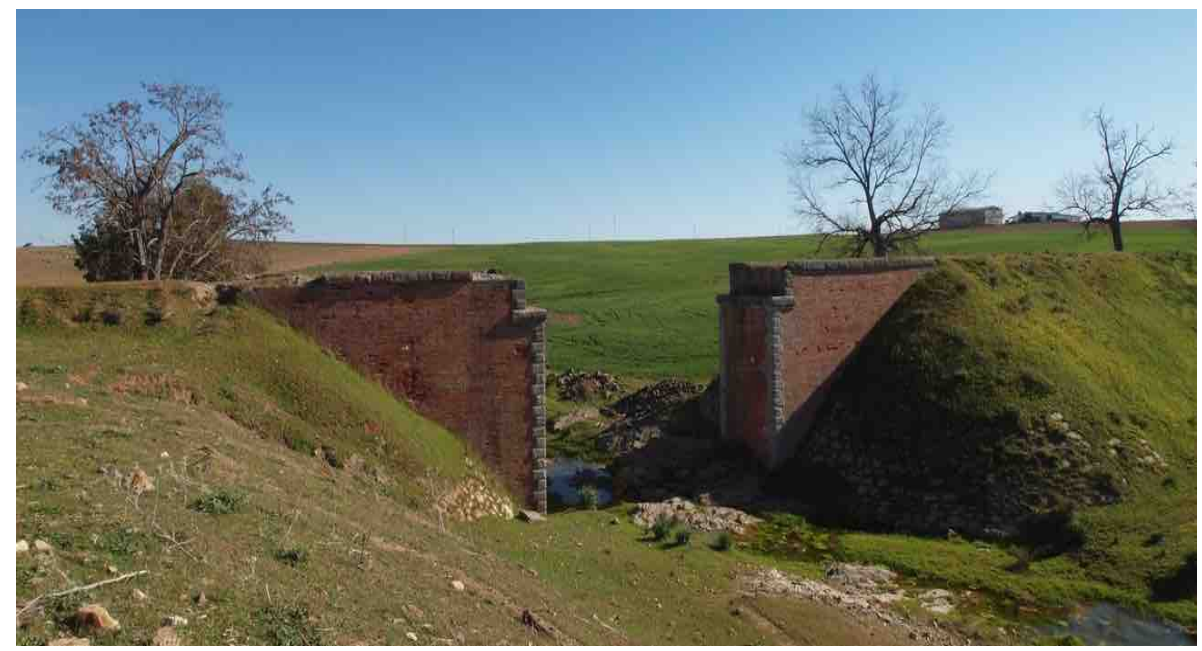




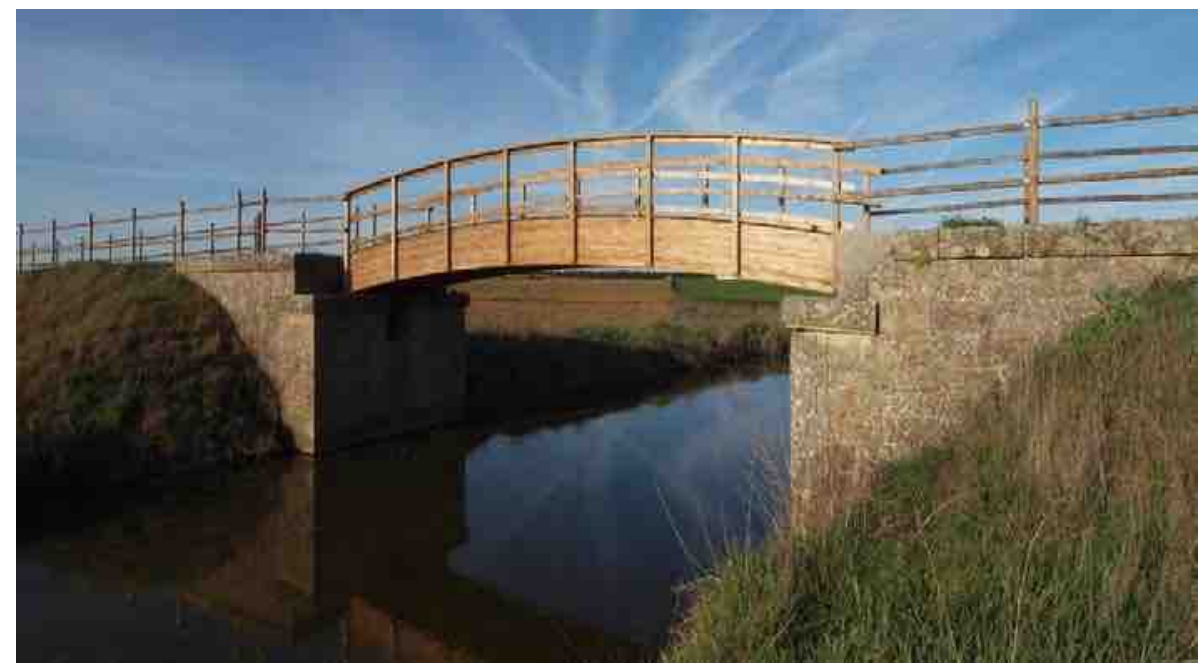

Fig. 16. Puente interrumpido sobre el río Bembézar, en las cercanías de Azuaga; puente restaurado aprovechando los antiguos estribos sobre el arroyo de San Pedro, junto a Fuente Obejuna.

Además de los puentes, hubo otras obras menores para dar continuidad a las vaguadas y puntos bajos de la traza ${ }^{17}$. Así, se proyectaron caños y tajeas, de hormigón o metálicas; incluso existían tajeas descubiertas, para cuando la altura del terraplén no permitía otra cosa. En este caso, se creaba un bastidor formado por dos vigas de roble de $0,22 \times 0,22 \mathrm{~m}$, entramadas, que podían soportar un peso de 5 toneladas, con anchura de $0,60 \mathrm{~m}$. Asimismo, se dispusieron alcantarillas de 2 y $3 \mathrm{~m}$, y pontones de $4 \mathrm{~m}$, de ladrillo, cantería y hormigón; según leemos en la Memoria, estos modelos se habían empleado ya en la línea de vía de ancho normal entre Linares y Almería. Estas obras, pese a su escasa relevancia, son aún visibles en algunos puntos de la traza -incluso algunos siguen prestando servicio-, y de nuevo muestran un buen hacer constructivo que sigue sorprendiendo tras más de una centuria.

17 Las obras de fábrica de hasta $4 \mathrm{~m}$ de luz formaban parte de un pequeño proyecto presentado el 8 de marzo de 1894 por Pablo Gal y el ingeniero de caminos Ángel Ochotorena Trujillo. Éste estaba referido a los modelos de las obras de fábrica de $4 \mathrm{~m}$ de luz e inferiores. Los proyectos de obras de luz superiores serían sometidos ulteriormente a la aprobación (AGA 25/07108) 

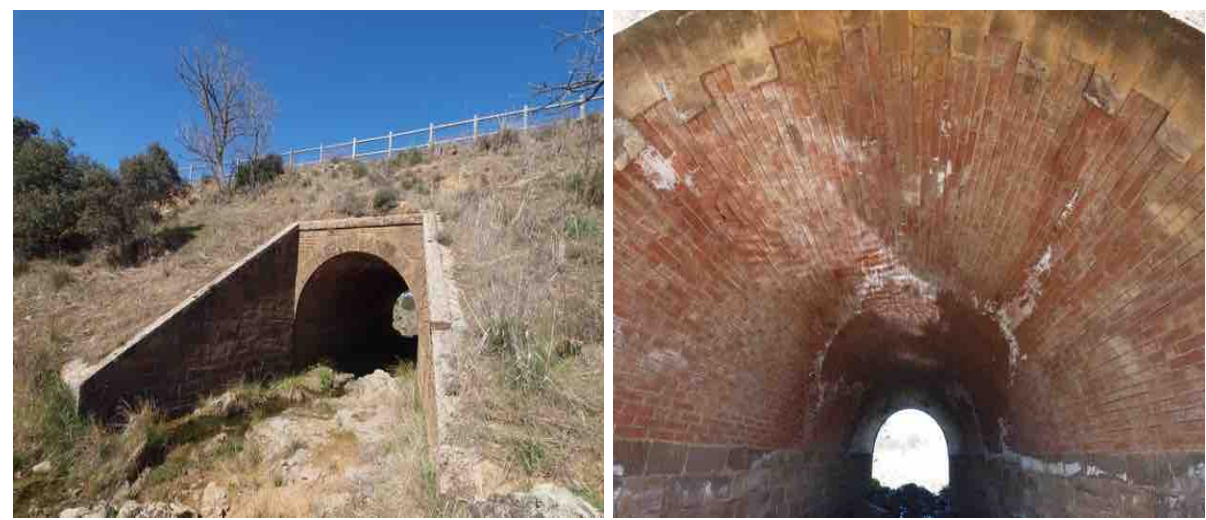

Fig. 17. Pontón de $4 \mathrm{~m}$ sobre el arroyo Sotillo, junto a Fuente del Arco. Hoy sigue en servicio, como parte de la traza de la vía verde La Jayona. Destaca el interior de la bóveda, de ladrillo visto y remates en sillería, que sorprenden aún por la albañilería

\section{CONCLUSIONES}

La investigación realizada permite obtener varias conclusiones. En primer lugar, se constata que los restos de la infraestructura de la antigua línea Peñarroya a Fuente del Arco siguen siendo visibles en su mayor parte: la traza destaca merced a los movimientos de tierra, la mayor parte de los edificios siguen en pie -si bien en lógico estado de ruina-, y los estribos de las estructuras aún pueden distinguirse en los cauces principales.

Algunos de estos elementos han sido reutilizados, mediante vías verdes, mediante caminos agrícolas o incluso formando parte de la actual pista de aterrizaje de un aeródromo. Este reciclaje de la antigua línea ferroviaria, si bien de forma desigual, prolonga la existencia y el mantenimiento de determinados tramos y construcciones singulares de la vieja infraestructura en el paisaje de nuestros días.

Otras unidades de la antigua obra han desaparecido por completo: los componentes reaprovechables como traviesas, carriles o estructuras metálicas fueron retirados tras la supresión de la línea. Además, algunas partes de la traza han desaparecido como consecuencia de la construcción de nuevas infraestructuras y edificaciones en el territorio. Esta circunstancia es problemática de cara a una eventual puesta en valor mediante vía verde en todo el recorrido; otra pérdida que debe ser incluso denunciada es la debida a la ocupación de estos 
terrenos por parte de las fincas aledañas: posiblemente los terrenos de la traza, junto con sus servidumbres, sean aún de propiedad pública.

Por otra parte, la comparación entre la obra proyectada -y creemos que construida-, y los restos actuales nos sugiere una serie de reflexiones. Las construcciones que perviven constituyen elementos singulares en el territorio, y son ejemplo de la gran transformación que llevaba consigo la implantación de una infraestructura ferroviaria en zonas marcadamente rurales. Por ello deberían llevarse a cabo iniciativas para consolidar y proteger los elementos que siguen distinguiéndose sobre el terreno, ya que nos permiten mantener la memoria de la comarca y de su devenir histórico. El territorio, siempre complejo, precisa de la pervivencia de dichas construcciones -aun en ruinas- para facilitar la lectura de los acontecimientos pasados que transformaron el mismo; la sucesiva adición de capas -de historia e historias- a la superficie final de la región -a lo visible, a lo perceptible, al paisaje en definitiva- es compatible con el mantenimiento de las capas previas: sin esas capas, de hecho, carece de sentido hablar de paisaje completo.

Así, por ejemplo, la existencia de las casillas de guardia permite distinguir qué caminos existían ya hace más de ciento veinticinco años en los campos atravesados por el ferrocarril: la ausencia de camino en algunos cruces muestra la pérdida de estos, y la posible desaparición de algunas casillas provoca también la eliminación de esa referencia y reconocimiento al camino, quizá todavía presente.

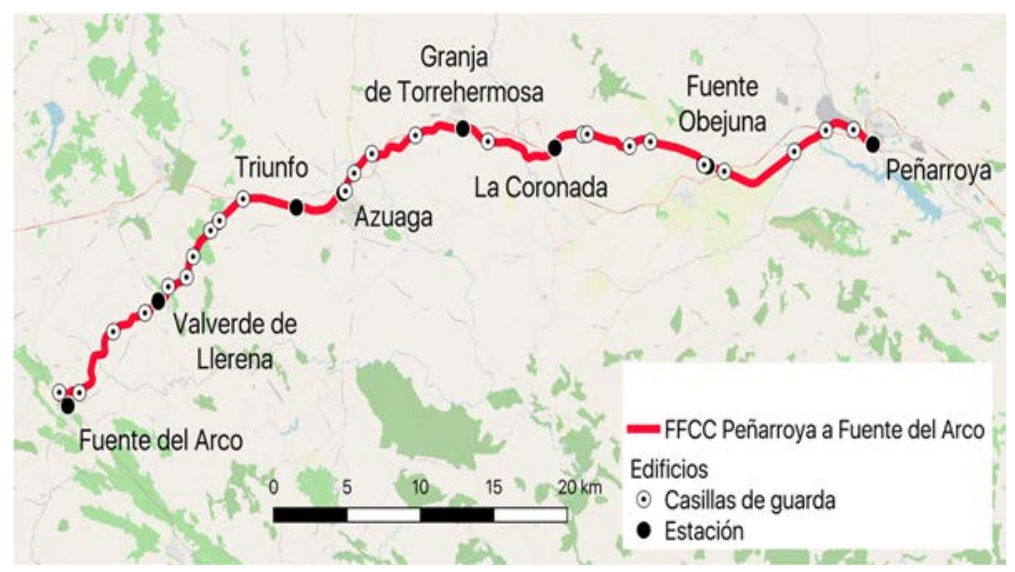

Fig. 18. Situación de las casillas de guarda y estaciones a lo largo de la línea (elaboración propia) 
La investigación deja aún pendiente el estudio de la situación actual de algunas edificaciones y estructuras que no han podido ser visitadas. Para ello sería preciso el empleo de otras herramientas que puedan completar la información recopilada en archivos y visitas de campo: el empleo de drones, ya usados con éxito en el estudio de vías ferroviarias en servicio, podría facilitar la observación del estado real de algunas casillas de guardia, de algunos puentes y de otros edificios de difícil o imposible acceso a pie o en automóvil estándar. A modo de ejemplo, la visita de campo, también las imágenes aéreas existentes, han permitido identificar hasta 25 casillas de guarda, pero posiblemente existan aún algunas más; también sería interesante analizar las estructuras mineras que se intuyen gracias a las imágenes cenitales, y que comprenderían cargaderos al pie de las vías ferroviarias, pero se encuentran en lugares de difícil acceso.

Por último, las aportaciones de esta investigación ponen de relieve, como también lo hacían los textos citados relacionados con este ferrocarril al inicio de este artículo, la necesidad de proteger y poner en valor los importantes restos aún visibles de las infraestructuras de la SMMP, que constituyen un importante patrimonio industrial y de la ingeniería civil de toda el área estudiada.

\section{Pedro Plasencia-Lozano}

Departamento de Construcción e Ingeniería de Fabricación Área de Ingeniería e Infraestructura de los Transportes

Universidad de Oviedo C/ Pedro Puig Adam Sede Departamental Oeste. Módulo 7. $1^{\text {a }}$ Planta 33203 Gijón (España) https://orcid.org/0000-0001-5240-0733 plasenciapedro@uniovi.es 